Supplement of Hydrol. Earth Syst. Sci., 20, 4159-4175, 2016

http://www.hydrol-earth-syst-sci.net/20/4159/2016/

doi:10.5194/hess-20-4159-2016-supplement

(C) Author(s) 2016. CC Attribution 3.0 License.

(c) (1)

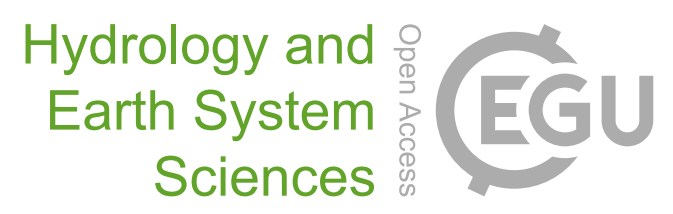

Supplement of

\title{
Using an integrated hydrological model to estimate the usefulness of meteorological drought indices in a changing climate
}

D. von Gunten et al.

Correspondence to: Olaf A. Cirpka (olaf.cirpka@uni-tuebingen.de)

The copyright of individual parts of the supplement might differ from the CC-BY 3.0 licence. 


\section{Definition of drought indices}

This section provides an overview of the selected drought indices, which were shortly presented in Section 2.6.

\subsection{Standardized precipitation index (SPI)}

SPI (McKee et al., 1993; Svoboda et al., 2012) is a widely-used drought index (Zargar et al., 2011). To compute this index, precipitation data is first fitted to a probability distribution. We use a gamma distribution with the shape parameter $\alpha$ and the scale parameter $\beta$ (Wu et al., 2005). The fitted parameters $\hat{\alpha}$ and $\hat{\beta}$ are then used to find the cumulative probability $G(P)$ of the precipitation amount $P$ (Edwards, 1997):

$$
G(P)=\int_{0}^{P} g(x) d x=\frac{1}{\hat{\beta}^{\hat{\alpha}} \Gamma(\hat{\alpha})} \int_{0}^{P} x^{\hat{\alpha}-1} e^{\frac{-x}{\hat{\beta}}} d x
$$

where $\Gamma$ is the gamma function or $\Gamma(\alpha)=\int_{0}^{\infty} x^{\alpha-1} e^{-x} d x$. The probability of null precipitation $q$ is estimated by dividing the number of dry months by the length of the monthly time series. It is accounted for by:

$$
H(P)=q+(1-q) G(P)
$$

To compute the value of SPI, an equiprobability transformation is made from the cumulative probability $H(P)$, i.e., $H(P)$ is transferred to a standard normal random variable with a mean of zero and a variance of unity:

$$
S P I=\Phi^{-1}(H(P))
$$

where $\Phi$ is the standard normal cumulative distribution function. SPI takes monthly precipitation as input and can be computed at various time scales, from 1 month to 24 months. In this study, we use a 12-months time scale. An SPI-value smaller than -1 indicates a dry period, and an SPI-value larger than +1 a wet period (Svoboda et al., 2012).

\subsection{Standardized precipitation evapotranspiration index (SPEI)}

SPEI (Vicente-Serrano et al., 2009) has been developed to account for the impact of potential evapotranspiration on droughts, especially in a changing climate. Its computation is similar to SPI. For SPEI, the difference between precipitation and potential evapotranspiration, rather than only precipitation, is used in the index computation. This time series is fitted to a probability distribution as described 
for SPI. A log-logistic distribution (e.g., Ashkar and Mahdi, 2006) is used here, following Vicente-Serrano et al. (2009). The sensitivity of SPEI to potential evapotranspiration is higher than other drought indices (Vicente-Serrano et al., 2015), such as PDSI or RDI (defined in Sect. 1.5 and 1.6).

\subsection{Rainfall anomaly index (RAI)}

RAI can be used to analyze dry or wet periods. When used to study droughts, RAI (e.g., Keyantash and Dracup, 2002) represents a ranking of yearly precipitation, compared to the most negative precipitation anomalies recorded. It is defined as follows:

$$
R A I=-3 \frac{P-\bar{P}}{\bar{E}-\bar{P}}
$$

where $P$ is the annual precipitation, $\bar{P}$ the mean annual precipitation and $\bar{E}$ is the precipitation average of the ten driest years. Negative values of RAI indicate dry periods.

\subsection{Effective drought index (EDI)}

In contrast to the other drought indices, EDI (Byun and Wilhite, 1999) is computed using daily precipitation to better take into account the effect of precipitation variability on droughts. The effective precipitation $E P$ is calculated first:

$$
E P=\sum_{n=1}^{i} \frac{\sum_{d=1}^{n} P_{d}}{n}
$$

where $i$ is the summation period and $P_{d}$ is the precipitation of $d$ days before the end of the period $i$. We choose $i=365$ days in our application, i.e., annual averages. $\mathrm{EP}$ is then normalized to calculate the EDI:

$$
E D I=\frac{E P-\overline{E P}}{\sigma_{E P}}
$$

where $\overline{E P}$ is the mean of the effective precipitation $(E P)$ and $\sigma_{E P}$ its standard deviation.

\subsection{Palmer drought severity index (PDSI) and Palmer hydrological drought index (PHDI)}

PDSI was developed by Palmer (1965) to better consider the role of evapotranspiration on droughts and to "measure the cumulative departure of moisture supply" 
during dry periods. This index is composed of a simplified water balance of a basic two-layer soil model which is then compared to a reference water balance time series. It is a dimensionless number, usually ranging between -4 and +4 , with negative values indicating dry periods (Keyantash and Dracup, 2002). It is widely used, especially in the United States, but it is relatively involved to calculate (Jacobi et al., 2013). In addition, it assumes a homogeneous soil type and the time window considered by the index varies depending on the weather.

PHDI (Palmer, 1965) is a variation of the previous index which has been developed to better represent hydrological droughts. To achieve this, PHDI applies the same simplified soil model as PDSI, but stricter criteria are used to define the limits of the wet and dry periods. This results in an index which reacts more gradually than the original Palmer index (Keyantash and Dracup, 2002).

In this study, we use the Matlab tool developed by Jacobi et al. (2013) to calculate PDSI and PHDI.

\subsection{Reconnaissance drought index (RDI)}

The RDI (Tsakiris and Vangelis, 2005) is based on the FAO aridity index $\alpha_{i}$, defined as:

$$
\alpha_{i}=\frac{\sum_{j=1}^{12} P_{j i}}{\sum_{j=1}^{12} P E T_{j i}}
$$

where $P_{j i}$ is the monthly precipitation of the year $i$ and $P E T_{j i}$ is the monthly potential evapotranspiration. The standardized RDI is computed as followed (Tsakiris and Vangelis, 2005):

$$
R D I=\frac{\ln \left(\alpha_{i}\right)-\overline{\ln \left(\alpha_{i}\right)}}{\sigma_{\ln \left(\alpha_{i}\right)}}
$$

where $\sigma_{\ln \left(\alpha_{i}\right)}$ is the standard deviation of the natural logarithm of the aridity index and $\overline{\ln \left(\alpha_{i}\right)}$ its mean.

\section{Computation of potential evapotranspiration}

In this section, we give more precision concerning our computation of potential evapotranspiration $\left(\mathrm{ET}_{0}\right)$, sometimes referred to as reference evapotranspiration.

$\mathrm{ET}_{0}$, which is used in the calculation of SPEI, PDSI, PHDI, and RDI is estimated using the FAO Penman-Monteith equation (Allen et al., 1998), defined as follows: 


$$
E T_{0}=\frac{0.408 \Delta\left(R_{n}-G\right)+\gamma \frac{900}{T+273} u_{2}\left(e_{s}-e_{a}\right)}{\Delta+\gamma\left(1+0.34 u_{2}\right)}
$$

where $R_{n}$ is the net radiation at the crop surface [ $\mathrm{MJ} \mathrm{m}^{-2}$ day $\left.^{-1}\right], T$ represents the mean daily air temperature $\left[{ }^{\circ} \mathrm{C}\right], u_{2}$ indicates the wind speed at two meters above ground $\left[\mathrm{m} \mathrm{s}^{-1}\right],\left(e_{s}-e_{a}\right)$ symbolizes the saturation vapor pressure deficit $[\mathrm{kPa}], \Delta$ is the slope of the vapor pressure curve $\left[\mathrm{kPa}^{\circ} \mathrm{C}^{-1}\right], \gamma$ depicts the psychrometric constant $\left[\mathrm{kPa}^{\circ} \mathrm{C}^{-1}\right]$, and $G$ represents the soil heat flux density $\left[\mathrm{MJ} \mathrm{m}^{-2} \mathrm{day}^{-1}\right.$ ], assumed to be zero in our analysis.

Some indices, for example PDSI, are often computed using simpler expressions for potential evapotranspiration that are based only on temperature, such as the Thornthwaite equation (Jacobi et al., 2013). However, we compute all indices with identical $\mathrm{ET}_{0}$ to avoid an undue influence on the performance of the drought indices by the choice of $\mathrm{ET}_{0}$.

The hydrological model, described in Sect. 2.3 of the method section, also uses daily inputs of reference evapotranspiration as estimated by the FAO PenmanMonteith equation (Allen et al., 1998). $\mathrm{ET}_{0}$ is then multiplied by a time-varying crop coefficient to account for the different crop types and their spatial distribution in the catchment. Hence, the final model input is the spatially-explicit daily crop evapotranspiration under standard conditions $\left(\mathrm{ET}_{c}\right)$, corresponding to the maximum evapotranspiration of each crop without water limitation. The crop coefficients are taken from Allen et al. (1998). Although $\mathrm{ET}_{c}$ is used to simulate hydrological impacts, it is not used in the computation of drought indices. Here, we use $\mathrm{ET}_{0}$ in all calculations. This is consistent with the approaches used in other studies. We want to mimic the typical utilization of drought indices, which are usually computed directly from meteorological data (e.g., Zarch et al., 2015). To test the impact of our assumption, we repeated the analysis presented in this paper using $\mathrm{ET}_{c}$ instead of $\mathrm{ET}_{0}$ (results not shown) and found very similar correlations and relationships between drought indices and hydrological variables.

The potential evapotranspiration used by the hydrological model and in the computation of drought indices is calculated from the outputs of a weather generator (Sect. 2.4 of the method section). To validate the outputs of the weather generator (Sect. 3.2), time series of potential evapotranspiration are prepared, based on measured time series. More precisely, we use 23 years of precipitation and temperature (1988-2011) measured at the meteorological station of Ejea de los Caballeros (Sect. 2.2). Time series of radiation, wind, and relative humidity are also needed to calculate $\mathrm{ET}_{0}$. However, these variables are only measured for the last 9 years. For the 14 years with missing data, $\mathrm{ET}_{0}$ is calculated using the daily mean radiation, wind, and relative humidity averaged over the last 9 years and on the actual mea- 
surement of temperature. Differences between the usual calculation of $\mathrm{ET}_{0}$ and the calculation based on averaged radiation, relative humidity, and wind are small. The Nash-Sutcliffe efficiency (Nash and Sutcliffe, 1970) between the $\mathrm{ET}_{0}$ using the full data set and the $\mathrm{ET}_{0}$ based on averaged data is above 0.85 for the 9 last years.

\section{Detailed comparison of the correlation coefficients}

We analyze here the dependency between the different drought indices, listed in the main publication, and the corresponding simulated mean annual discharge, water deficit, and hydraulics heads. For this purpose, we use the Pearson's linear correlation coefficient $r$ between the drought indices and the hydrological variables:

$$
r=\frac{\operatorname{cov}(D I, x)}{\sigma_{D I} \sigma x}
$$

where cov is the covariance, $D I$ is the value of the drought index and $x$ is the hydrological variable under consideration. The range of $r$ is -1 to +1 , where +1 indicates a perfect positive correlation, -1 is a perfect negative correlation, and a value of zero signifies no correlation.

We conduct the same analysis for present and future climates, and for the different irrigation scenarios. Irrigation and climate scenarios are described in the main publication. The results are summarized in Figure 1 and are subsequently discussed. It is important to note that the correlation coefficients only test whether a linear relationship between two sets exists, regardless of the coefficients of the corresponding linear regression (see Section 7 of the publication).

\subsection{Comparison for present climate conditions}

For the present climate, discharge and water deficit are reasonably well correlated with drought indices $(|r|>0.5$, Figure 1, left column). For hydraulic heads, the correlation coefficient is generally poor (between 0.2 and 0.5, not shown in Figure 1). Hydraulic heads respond slower to drought than discharge and water deficit. Therefore, a lag-time between drought index and hydraulic head response can be expected. This was confirmed by a cross-correlation analysis, which shows a delayed response in some of the wells (e.g., PO8), but no evidence of time-lags in others (e.g., PO10). Correlation coefficients between hydraulic heads and drought indices in Figure 1 incorporate these time-lags, i.e., the correlation coefficients shown are the maximum correlation coefficients between hydraulic heads and the drought indices of 1-16 months before. Because the responses of the aquifer to the meteorological conditions are non-linear, the reasons for these differences between the wells are difficult to explain. Observation wells situated in the highest part of 
the aquifer (e.g., PO8) are generally more sensitive to drought because the fluctuations of the water table are larger in this part of the catchment. In the lower part of the catchment, dry periods are not sufficient to significantly lower the water table because of the large water storage.

Between the different drought indices, RAI, RDI, and SPEI exhibit the largest correlation with discharge and water deficit. For these indices, the correlation coefficient varies between $r=0.76$ and $r=0.82$ for annual discharge and $r=-0.78$ and $r=-0.81$ for water deficit (Figure 1, panels a and c). Indices EDI and PDSI show the smallest correlation (between 0.41 and 0.59 for discharge). PDSI was developed for the climate of the Great Plains in USA (Zargar et al., 2011) and, as our study concentrates on Mediterranean climate, a lower correlation for this index can be expected. In our study, the added information of daily variability of precipitation, as considered by the EDI index, did not improve the quality of the prediction. The relatively low correlation between EDI and discharge is probably a consequence of the different weights given to the precipitation data. Equation 1.4 shows that the precipitation at the end of the yearly time series is given more weight than the precipitation at the start of the time series. This choice reduces the correlation with annual mean discharge and yearly water deficit. Correlation of drought indices with hydraulic heads in a particular observation well is similar for all indices, even if large differences were computed between the wells.

Overall, our results for the current climate (Figure 1, left column) are in agreement with earlier studies. For example, Vicente-Serrano et al. (2012) compared the correlation between standardized stream flow at monthly time scale (which is an estimation of average discharge) and 6 drought indices, including SPI, SPEI, PDSI, and PHDI. Similar to our results, SPEI showed the best correlation with discharge. SPI had a lower correlation than SPEI, but the difference was relatively small in both studies. In our case, the correlation coefficient of SPI with mean annual discharge is 0.68 , while the correlation with SPEI is 0.83 in the non-irrigated case.

In general, simpler indices based on precipitation only, e.g., SPI or RAI, exhibit similar or larger correlation with the studied hydrological variables than indices that include $\mathrm{ET}_{0}$ (Figure 1, panels a and c). For example, SPEI has the largest correlation with annual discharge in present climate $(r=0.81$, average of both land-use scenarios), but RAI exhibits a very similar correlation $(r=0.80)$. This results is consistent with findings of previous studies (e.g., Keyantash and Dracup, 2002). Indices based only on precipitation also correlate well with water deficit because precipitation correlates strongly with water deficit $(r=-0.75)$, and, hence, also with drought indices based only on precipitation (Figure 1, panel c). However, the correlation between the changes of precipitation and water deficit in different climates is low. For example, the water deficit increases in the hydro- 
logical simulations driven by the future time series of meteorological inputs from all considered climate models, but the annual mean precipitation increases in some climate models and decreases in others. This situation might be problematic for accurate climate-change impact predictions.

\subsection{Comparison between present and future climates}

The correlation coefficients between drought indices and hydrological variables in future climate are computed for each climate scenario (defined by the different regional climate models) and then averaged over the scenarios. The results differ widely between the regional climate models. In the most severe case, the correlation coefficient between discharge and EDI is 0.18 using the ETHZ model, while a value of 0.55 is attained using the MPI model (Figure 1, panel b). This difference between the climate scenarios is nevertheless lower when the drought index correlates well with the hydrological variable. For example, the maximal difference between the correlation coefficient $r$ for the four climate scenarios is 0.2 for the three best indices (RAI, RDI, and SPEI) and discharge.

The correlation coefficients between the drought indices and the hydrological variables for present and future climates are quite similar (Figure 1, left and right columns). The average difference between the present and future correlation coefficients of discharge and drought indices is only 0.02 (average of the four climate scenarios). Moreover, the drought indices which correlate best with discharge in present climate (RAI, SPEI, and RDI, $0.76<=r<=0.82$ ) show also the best correlation with future discharge $(0.73<=r<=0.84)$. In addition, for water deficit, the indices which correlate well in present climate do so in future climate. The correlation coefficients of hydraulic heads and drought indices are similar in present and future climates, too.

\subsection{Comparison between different land-uses in present and future cli- mates}

The correlation of drought indices and hydrological variables is similar for the different irrigation scenarios (Figure 1). Drought indices which correlate best in scenarios with irrigation (PIRR, FUTIRR) correlate similarly well in the scenario without irrigation (NOIRR).

Drought indices correlate slightly better with discharge in the scenario without irrigation compared to scenarios that include irrigation (average difference in correlation: 0.04 in present climate, 0.03 in future climate). This result is nevertheless consistent for all indices in present and future climates. This can easily be explained as the drought indices consider only precipitation as water input, whereas 
discharge is of course affected by irrigation water.

For water deficit, no consistent differences in the correlation coefficient between the two irrigation scenarios are observed in the present climate (Figure 1, panel c). In future climate, the correlation between drought indices and water deficit is slightly larger in the scenario without irrigation (Figure 1, panel d). The difference is small (on average: 0.08), but consistent for all indices. As stated above, irrigation is an additional source of water not accounted for in the drought indices. Irrigation influences actual evapotranspiration and its influence increases in future climate because of the warmer conditions. Hence, the drought indices correlate less with water deficit when irrigation is present and the decrease in correlation is more pronounced in the future.

For hydraulic heads, the influence of the irrigation scenarios depends on the location of the wells. Observation wells situated at higher surface elevation (e.g., PO8) do not show large differences in the correlation coefficient between the irrigated and non-irrigated scenarios (average difference: 0.04 in present climate). However, hydraulic heads in the wells in the lowest part of the catchment (e.g., PO10) show larger differences in the correlation coefficient (average difference: 0.12). As the majority of cultivated fields are situated in the lower parts of the catchment, most of the irrigation is applied in this area, resulting in a larger impact of irrigation on the hydraulic heads in this zone. PO8 correlates better with the drought indices when irrigation is present (Figure 1, panels e and f). PO10 shows the opposite behavior (Figure 1, panels $g$ and $h$ ). Indeed, irrigation has different impacts on the correlation coefficients for hydraulic heads: Firstly, as in the discharge case, correlation coefficients between hydraulic head and drought indices are smaller when irrigation is present because irrigation is an additional water source which is not directly considered. Secondly, irrigation raises the water table, resulting in an increased impact of climate on hydraulic heads (von Gunten et al., 2015) and so in a larger correlation with drought indices. The relative importance of these effects depends on the position and depth of the observation well.

\section{References}

Allen, R., Pereira, L., Raes, D., and Smith, M. (1998). Crop evapotranspiration (guidelines for computing crop water requirements). FAO irrigation and drainage paper, 56.

Ashkar, F. and Mahdi, S. (2006). Fitting the log-logistic distribution by generalized moments. J. Hydrol., 328:694 - 703. 
Byun, H.-R. and Wilhite, D. (1999). Objective quantification of drought severity and duration. J. Climate, 12:2747-2756.

Edwards, D. (1997). Characteristics of 20th century drought in the United States at multiple time scales. $\mathrm{PhD}$ thesis, Colorado State University.

Jacobi, J., Perrone, D., Duncan, L. L., and Hornberger, G. (2013). A tool for calculating the Palmer drought indices. Water Resour. Res., 49(9):6086-6089.

Keyantash, J. and Dracup, J. A. (2002). The quantification of drought: An evaluation of drought indices. B. Am. Meteorol. Soc., 83(8):1167-1180.

McKee, T. B., Doesken, N. J., and Kleist, J. (1993). The relationship of drought frequency and duration to time scales. Eighth Conference on Applied Climatology, Anaheim, California, 1:179-184.

Nash, J. and Sutcliffe, V. (1970). River flow forecasting through conceptual models, part I- a discussion of principles. J. Hydrol., 10:282-290.

Palmer, W. (1965). Meteorological drought. Office of Climatology, U.S. Departement of commerce, 45:1-58.

Svoboda, M., Hayes, M., and Wood, D. (2012). Standardized precipitation index user guide. World Meteorological Organization, 1090:1-24.

Tsakiris, G. and Vangelis, H. (2005). Establishing a drought index incorporating evapotranspiration. European Water, 9:3-11.

Vicente-Serrano, S., Beguería, S., and López-Moreno, J. I. (2009). A multiscalar drought index sensitive to global warming: The standardized precipitation evapotranspiration index. J. Climate, 23:1696-1718.

Vicente-Serrano, S. M., Beguería, S., Lorenzo-Lacruz, J., Camarero, J., LópezMoreno, J., Azorin-Molina, C., Revuelto, J., Morán-Tejeda, E., and SanchezLorenzo, A. (2012). Performance of drought indices for ecological, agricultural, and hydrological applications. Earth Interact., 16:1-27.

Vicente-Serrano, S. M., van der Schrier, G., Beguería, S., Azorin-Molina, C., and López-Moreno, J. I. (2015). Contribution of precipitation and reference evapotranspiration to drought indices under different climates. J. Hydrol., 526:42-54.

von Gunten, D., Wöhling, T., Haslauer, C., Merchán, D., Causapé, J., and Cirpka, O. (2015). Estimating climate-change effects on a Mediterranean catchment under various irrigation conditions. J. Hydrol. Reg. Stud., in press. 
Wu, H., Hayes, M. J., Wilhite, D. A., and Svoboda, M. D. (2005). The effect of the length of record on the standardized precipitation index calculation. Int. J. Climatol., 25:505-520.

Zarch, M. A. A., Sivakumar, B., and Sharma, A. (2015). Droughts in a warming climate: A global assessment of standardized precipitation index (SPI) and reconnaissance drought index (RDI). J. Hydrol., 526:183-195.

Zargar, A., Sadiq, R., Naser, B., and Khan, F. I. (2011). A review of drought indices. Environ. Rev., 19:333-349. 

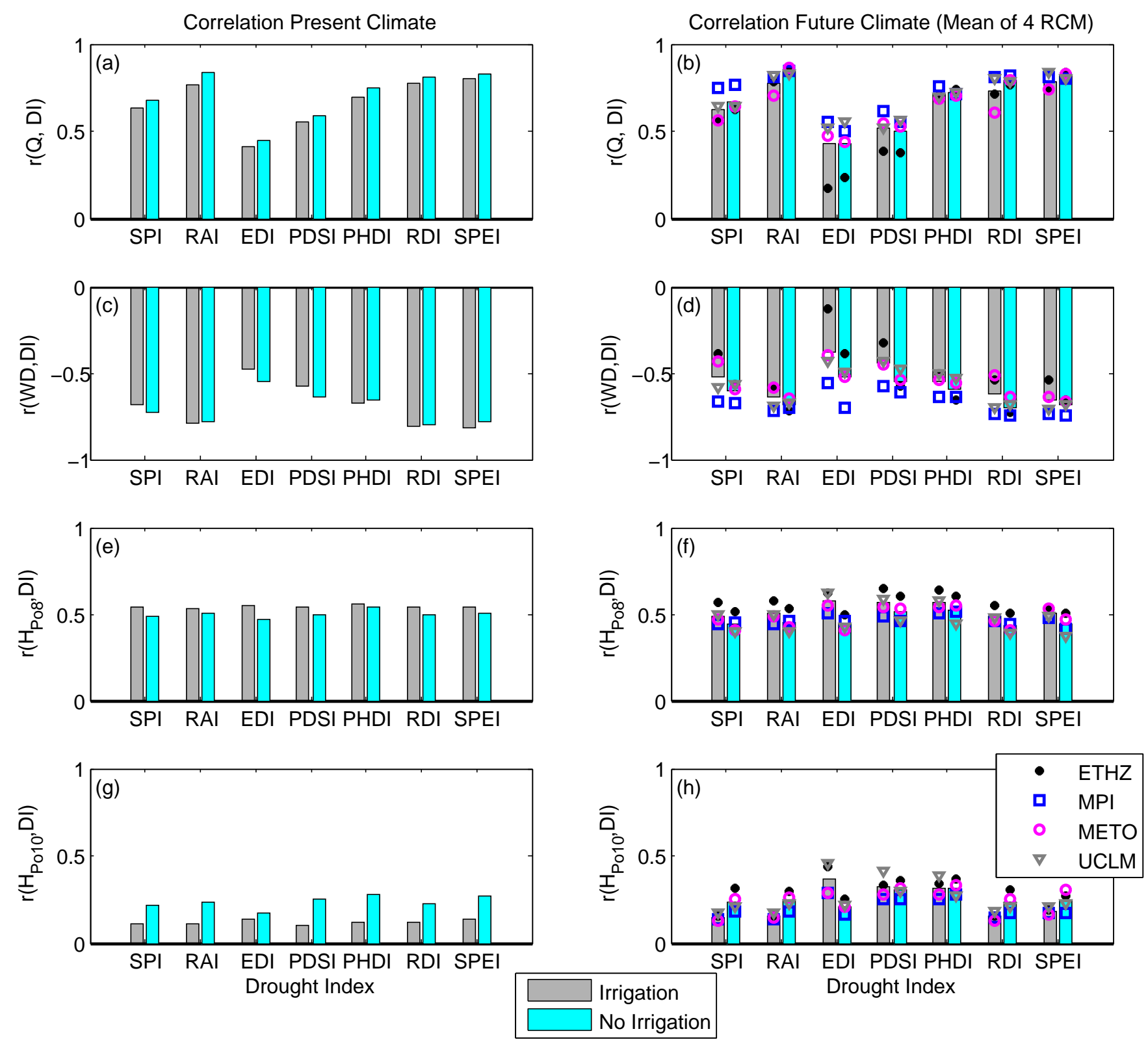

Figure 1: Correlation coefficients $r$ between the drought indices (DI) and the hydrological variables (discharge, water deficit, and hydraulic heads). In future climate (right column), the plotted bars are the average of the outputs of the four regional climate models. See Table 2 of the publication for information about the climate models. 